\title{
The Relationship between Hours of Television Watching and Academic Achievement of Secondary School Students: The Case of Some Selected Secondary Schools in Harer City
}

Ambachew Tarekegn*, Sofiya Endris

Haramaya University, Ethiopia

Corresponding author: Ambachew Tarekegn, E-mail: ambachewt4@gmail.com

\section{ARTICLE INFO}

Article history

Received: May 08, 2019

Accepted: July 21, 2019

Published: July 31, 2019

Volume: 7 Issue: 3

Conflicts of interest: None

Funding: None

\begin{abstract}
The purpose of this study was to examine the relationship between hours of television watching and student academic achievement. The major objectives of study were examining the status of students' television watching and the relationship between hours of television watching and academic achievement. There has been a great debate among researchers regarding this area of concern. Some support the contribution of television to academic achievement and others argue that television watching negatively influences academic achievement. Two hundred students were randomly selected for the study. Data were collected through a structured questionnaire. The data collected through questionnaire were analyzed using both descriptive and inferential statistical methods. Students' background information and their hours of television watching were analyzed using descriptive statistics. On the other hand, the relationship between hours of television watching and academic achievement was analyzed by Pearson moment correlation. The results show there is no statistically significant relationship between hours of television watching and academic achievement of students. Based on this, it can be concluded that television may not have a significant effect on students' academic achievement by itself.
\end{abstract}

Key words: Television Watching, Academic Achievement, Secondary School

\section{INTRODUCTION}

Television is an electronic device which transmits picture and sound. It is used for entertainment, information and commercials. With the advent of satellite and digital technologies, there are unlimited programs on television. For instance, there are programs on news, education, culture, weather forecast, sports, music and a plethora of both good quality and inappropriate contents (Santrock, 2005). Television combines the appealing features of the movies and radio and it is one of the most popular amusement devices during the childhood years. It may lure children away from other forms of play.

As Syed (2010) explains, television is an electronic carpet that transports millions of persons each day to far of places. It is a new media of transmission which made its impression on every aspect of the world life. It is bouncing its signal on space satellites and uses oceanic cables to transmit live telecast to its beneficiaries. This electronic medium ensures its visibility without any global discrimination. It is reported that television made its visibility some more than sixty years ago. People were not only skeptical about it, but were also jealous, unkind and even hostile. Over a short span of time, however, it emerged as a remarkable medium of communication, entertainment and education. It needs to be mentioned that it found its space in all countries of the world and has transformed our planet into a 'gigantic electronic village' bringing various people and continents close (Bushan, 1992)

Television, as one form of media, plays a prominent role in children's life due to its widespread use and availability. In most homes, television is considered an integral part of the family activity that continues to take most of the young people's free time (Vittrup, 2009). Ever since its discovery, the impact it has on viewers' attitudes and behaviors has been a talking point that prompted several scholars to do a great deal of research (Harper-Gilmore, 1994).

Rodman 2006, states that "TV remains the most time consuming activity, and it remains the main source of news and information. It is the medium through which politics is conducted and it is humanity's main form of entertainment, it is also the world's most powerful sales tool." TV is a very powerful tool because it has the ability to break or make any society due to the fact that its medium has the ability to make the viewer's replicate actions they get exposed to; either in part or whole. That is why TV has become a very strong medium for advertising and other persuasive communications.

Ethiopian Television (ETV) was established in 1964, during the time of Emperor Haile Selassie, with the technical help of the British firm, Thomson. ETV was initially established to highlight the Organization of African Unity (OAU) 
founding heads of state meeting in Addis Ababa in that same year. Color television was introduced in 1982 by the military government in order to commemorate the founding of the Workers' Party of Ethiopia (WPE). Since its establishment, ETV has remained in the hands of government, with its operations and content regulated by government. These days the common complaint about ETV is of a gradual decline in the quality of its programs (Simon, 2005). Some viewers, especially in Addis Ababa, subscribe to the South African-based Multi-Choice Africa DStv satellite pay-tv service and the Arab Sat satellite service.

The subscription of the aforementioned and other satellite channels expose students for a wider television content and time. Now a days it's not uncomment to see students arguing and discussing about different films, music and other recreational television program as their major concern. When we closely look at the contents broadcasted by television most of them are recreational. This makes the students to fully concentrate and give the majority of their time for watching television. This motivates the researcher to scientifically investigate the problem.

There also is a dearth of local researches regarding the impact of television watching on academic achievement. Even those conducted focus on the general impact of television (Sharew, 2014), media regulation (Yilma, 2007) and broadcast coverage (Tafesse, 2006). Therefore, this study tries to fill the gap of these researches by assessing the impact of television watching on academic achievement of students.

\section{Research Questions}

It is worthwhile to empirically test the effect of watching television on student academic achievement by using empirical evidence. Hence, this study intends to address the issue by raising the following research questions.

1. Is there any statistically significant relationship between hours of television watching and academic achievement?

2. What is the status of students' Television watching?

\section{LITERATURE REVIEW}

Even with the many new technological developments, television viewing stays the main choice entertainment for many millions of people including children (Gunter \&McAleer, 1997). Currently, children around the world have access to a wide-ranging media more than any past generation.

The potential impacts of electronic media, particularly television, on children have long been criticized and people's belief on the part television plays on what children believe is right, wrong or possible has escalated the attention given to the topic (Fortman, Clarke, \& Austin, 1998). It has already been established that television can have both positive and negative effects on children's development depending on the content to which they are exposed. Some media messages can teach children positive, pro-social lessons, while others can lead to children learning antisocial lessons that encourage them to behave antisocially.

Parental mediation of television viewing have confirmed the belief that parents can play a huge role in curbing the neg- ative effects of television exposure and enhance the positive ones (An \& Lee, 2010). It could be said that parents remain central to regulating and guiding their children's television use to ensure that they engage in contents that positively influence their behavior. The roles parents play in regulating the media effects on their children is mainly determined by their attitude and concern towards the effect of television exposure (Nathanshon, 2001).

Studies on parental mediation have been considerably on the rise during the past few decades (Nathanson, 2001). Generally, these studies seek to understand how parents protect their children from the adverse effects of media in general and how parents through guidance teach their children to be critical viewers (Sandstig, Johansson, \& Ringsberg, 2013). Existing parental mediation literatures mainly evolve around the occurrence, predictors or effects of parental mediation (Valkenburg, Krcmar, Peeters, \& Marseille, 1999).

Literatures on parental mediation reveal that parental behavior regarding television significantly affects children's reaction to the medium (Nathanson, 2001). This is to say that the family is primarily responsible in instilling a good media use habit in their children through exemplifying a good media use habit themselves. In addition, as television becomes prominent in the lives of children, it is mandatory for parents to take the leading position in regulating and guiding their children's television use.

Some studies have found a negative association between televisions viewing and educational attainment (Cooper, Valentine, Nye, \& Lindsay, 1999; Hancox et al., 2005). Neither of these studies, however, took into account the content of television watched. In fact, preschoolers who watched child-directed television programs, such as The Same Street, they achieved higher grades, read more books, and placed more value on academic achievement when they were adolescents (Anderson, Huston, Schmitt, Linebarger, \&Wright, 2001).

In addition, the programs created from research funded by the Ready to Learn Act has been associated with children having better attitudes towards going to school each day (Linebarger, Taylor-Piotrowski, \& Vaala, 2007, as cited in CPB \& PBS, 2011) as well as increased vocabulary knowledge of (Silverman, 2009, as cited in CPB \& PBS, 2011).

Still, some studies have found that TV use has little to no association with academic achievement (Shastri \& Mohite, 1997; Stevens, Barnard, \& To, 2009). Although good content is associated with positive outcomes for children, adult-directed programs can have adverse effects. For example, it has been suggested that heavy viewers of non-educational entertainment television during early kindergarten have lower reading ability scores in third grade, even after controlling for IQ, socioeconomic status (SES), and early literature score (Ennemoser \& Schneider, 2007). Likewise, one study found that children have poorer executive functioning when exposed to adult programs (Barr, Lauricella, Zack, \& Calvert, 2010). In sum, research suggests that whether television use is a detriment to children may depend on the content of the programs (Schmidt \& Anderson, 2007).

In a comprehensive examination of the literature over two decades, Comstock and Scharrer (1999) conclude that 
children who watch excessive television perform poorly on standardized achievement tests. Furthermore, it was discovered that excessive media usage negatively affects school performance because viewing replaces time that might otherwise be spent reading or engaged in alternate school-related activities.

The researchers have also found that children's writing is often similar in style to television show scripts, which are often fragmented and disconnected without regard to logic. Henke (1999) found that $39 \%$ of children stated they would prefer to surf the Internet than to engage in their favorite after-school activity. Time spent in educational activities and social interactions are negatively related to time watching educational television (Huston, Wright, Marquis, \& Green, 1999). Heavy viewers also are more likely to hold common cultural stereotypes, many of which are emphasized on television. In addition, those who watch excessive amounts of television and utilize other electronic media have little time for other critical life experiences, such as learning to play cooperatively with others.

\section{METHODS}

As it is mentioned earlier the purpose of this study was to examine the relationship between hours of television watching and academic achievement. In order to conduct this study a correlational research design was employed. This research design is selected because, this design is important to examine the relationship between two variables (Endawoke, 2011)

In this section, sampling techniques, instrument of data collection, and procedure followed in data collection presented.

\section{Participants}

With regard to sample size determination, Neuman (1997) pointed out some guiding principles that are followed by conventional social science researchers for selecting representative samples for quantitative studies. As stated by Neuman, if the study population is 1000 or under, the sample ratio would need to be 300 (about 30\%) individuals, for a population of 10,000 the sample size would be 1000 (about $10 \%$ ); and for populations over 150,000 , smaller sampling ratios $(1 \%)$ are acceptable. What this guideline makes clear is that as the target population increases, the sampling ratio decreases.

Thus, on the grounds those adolescents' of Harer city are homogeneous in order to select participants of the study from each school. In Harer city there are 5 government secondary schools and one preparatory school. In addition there are 5 private secondary school and 4 Private schools who teach secondary and preparatory school together. In General there are 14 secondary and preparatory schools in Harer city. From these 3 governments secondary school and 3 private secondary schools was selected (Table 1).

\section{Instrument of Data Collection}

A self-instrument questionnaire was used to collect data about the problem with investigation. The instrument has three parts. Part one is structured items mainly designed to gather background information about the participants. The second part of the instrument has an item that assesses students' degree of television watching.

\section{Method of Data Analysis}

Different statistical methods were utilized (ranging from simple descriptive ones to more complex statistical procedures in order to carry out the analysis depending on the nature of data available and the type of research questions set in order to be answered at the end of the study. The initial part of the analysis gives general description and explanation about major background data using frequency distribution, mean and standard deviations about the study population.In order to examine the relationship between television watching and academic achievement Pearson product moment correlation was employed. In order to examine the status of television watching frequency distribution and percentage were employed.

\section{RESULTS AND DISCUSSION}

In this section the background information of participants presented followed by the status of student television watching and its relationship with student academic achievement. In the analysis of the findings, different statically tools begging form simple descriptive to complex inferential statistics used. The type of statistical tests were selected on the basis of the nature of data available and the type of research questions set in order to be answered at the end of the study. The initial part of the analysis provided general description and explanation about major background. The initial part of the analysis provided general description and explanation about major background data using frequency distribution, mean and standard deviations about the study population. In order to check the status of student television watching frequency was used.

Table 1. Summary of samples drawn from each of the sampling frame

\begin{tabular}{llcccr}
\hline No & Name of the school & Female & Male & Total & No of participants selected \\
\hline 1. & Abadir secondary school & 385 & 516 & 601 & 61 \\
2. & Aboker preparatory school & 649 & 608 & 900 & 90 \\
3. & Betelhem academy & 182 & 128 & 310 & 30 \\
4. & Aw Abdal institute & 80 & 108 & 188 & 19 \\
5. & Total & 2604 & 2604 & 5208 & 200 \\
\hline
\end{tabular}

Source: Hareri Region Education Office, 2018 
In order to examine the relationship between student academic achievement and hours of television watching person moment correlation was used.

\section{Background of Participants}

As it can be observed in Table 2, 55\% of the participants are males and the rest $45 \%$ are females.

The majority of the participants (57\%) fall within the age bracket of 13-15 followed by participants within the age bracket of $16-18(35 \%)$ and $>18(5 \%)$ respectively. On the other hand the majority of the participant's (31\%) parents have only primary education and $22 \%$ of them have secondary education, $19 \%$ of the have secondary education and only 7 of parents have degree and above. The table also

Table 2. Background of participants

\begin{tabular}{lllcc}
\hline No & Characteristics & Option & Frequency & \% \\
\hline 1. & Sex of & Male & 110 & 55 \\
& respondents & Female & 90 & 45 \\
& & Total & 200 & 100 \\
2. & Age of & $13-15$ & 115 & 57.5 \\
& respondents & $16-18$ & 70 & 35 \\
& & T18 & 10 & 5 \\
& & Total & 200 & 100 \\
3. & Grade level of & Grade 9 & 100 & 50 \\
& respondents & Grade 10 & 100 & 50 \\
& & Total & 200 & 100 \\
4 & Parent Education & Religious & 18 & 9 \\
& status & education & & \\
& & Primary & 62 & 31 \\
& & education & & \\
& & Secondary & 44 & 22 \\
& & education & & \\
& & Certificate & 39 & 19 \\
& & College diploma & 24 & 12 \\
& & Degree and & 14 & 7 \\
& & above & & \\
& & Total & 200 & 100 \\
5 & Presence of & Yes & 198 & 99 \\
& television at & No & 2 & 1 \\
& home & Total & 200 & 100 \\
6. & Presence f & Yes & 198 & 99 \\
& satellite dish at & No & Total & 100 \\
\hline & home & & 200 & \\
\hline
\end{tabular}

Table 3. Students' hours of television watching in week days

\begin{tabular}{lcc}
\hline Time & Frequency & Percent \\
\hline None & 7 & 3.5 \\
$<1 / 2$ hour & 27 & 13.4 \\
$<1$ hour & 36 & 17.9 \\
$1-2$ hour & 87 & 43.3 \\
$2-3$ hour & 16 & 8.0 \\
$>3$ hour & 27 & 13.4 \\
Total & 200 & 99.5 \\
Total & 200 & 100.0 \\
\hline
\end{tabular}

shows that almost all of the participants (99\%) have both television and satellite dish in their home.

\section{Students' Hours of Television Watching in Week Days}

Table 3 shows that the majority of participants (43.3) watch television from 1-2 hours in a week day and $17.9 \%$ of them watch television during week day for an hour. Only $3.5 \%$ of the participants do not watch television at all during week days.

\section{Students' Television Watching Hours During Weekends}

Table 4 shows that during weekends $30.8 \%$ of participants watching television for $1-2$ hours, $22.5 \%$ of them watch

Table 4. In weekends how many times do you watch television?

\begin{tabular}{lcc}
\hline & Frequency & Percent \\
\hline None & 13 & 6.5 \\
less than half an hour & 30 & 15 \\
less than an hour & 17 & 8.5 \\
1-2hour & 62 & 30.8 \\
2-3hours & 34 & 16.9 \\
>3hour & 45 & 22.5 \\
Total & 200 & 100.0 \\
\hline
\end{tabular}

Table 5. Television program are mostly watched at home

\begin{tabular}{lcc}
\hline & Frequency & Percent \\
\hline News & 55 & 27.4 \\
Comedy & 48 & 23.9 \\
Documentary & 2 & 1.0 \\
Action film & 15 & 7.5 \\
Horror film & 2 & 1.0 \\
Sport & 23 & 11.4 \\
Drama & 46 & 22.9 \\
Music & 7 & 3.5 \\
Total & 200 & 100.0 \\
\hline
\end{tabular}

The television programs with the least frequency of being watch is documentary and horror film each comprise $1 \%$.

Table 6. Individuals that regulate students' television watching

\begin{tabular}{lcc}
\hline Individual & Frequency & Valid Percent \\
\hline Child him/herself & 88 & 45.1 \\
Father & 39 & 20.0 \\
Mother & 32 & 16.4 \\
Nanny & 11 & 5.6 \\
Sister/brother & 8 & 4.1 \\
Friend & 7 & 3.6 \\
Grand parent & 8 & 4.1 \\
Others & 2 & 1.0 \\
Total & 200 & 100.0 \\
\hline
\end{tabular}


The Relationship between Hours of Television Watching and Academic Achievement

Table 7. Relationship between television watching hours and students' academic achievement

\begin{tabular}{llcc}
\hline & & Academic achievement & Hours of television watching in a day \\
\hline Academic achievement & Pearson Correlation & 1 & -0.012 \\
& Sig. (2-tailed) & & 0.864 \\
& $\mathrm{~N}$ & 200 & 200 \\
Hours of television watching & Pearson Correlation & 0.012 & 1 \\
in a day & Sig. (2-tailed) & 0.864 & 200 \\
& $\mathrm{~N}$ & 200 & \\
\hline
\end{tabular}

more than 3 hours, $16.9 \%$ watch for $2-3$ hours and $6.5 \%$ of them do not watch at all.

\section{Television Programs Commonly Watched by Students}

The data in Table 5 gives information regarding the television program with the highest frequency of being watched is news $(27 \%)$ followed by comedy and drama which comprise 23.9 and $22.9 \%$ respectively.

The television programs with the least frequency of being watch is documentary and horror film each comprise $1 \%$.

\section{Family Members that Regulate Students' Television Watching}

As it is observed in Table 6, the majority of participant $88(45.1 \%)$ select the television program they watch for themselves followed by father $39(20 \%)$ and mother 32 (16\%).

\section{The Relationship between Students' Television Watching and Academic Achievement}

The data in Table 7 reveals that there is no statistically significant relationship between hours of television duration of students' television watching hours and their academic achievement.

\section{DISCUSSION}

Contrary to the researchers hypothesis the relationship between watching television and students' academic achievement is considerably low (is not statistically significant). This might be because of the presence of other mediating variables like parent controlling (regulating) of students television watching. Consistent with this finding (Shastri \& Mohite, 1997; Stevens, Barnard, \& To, 2009) found that TV use has little to no association with academic achievement. In addition some studies shows that Parental mediation of television viewing have confirmed the belief that parents can play a huge role in curbing the negative effects of television exposure and enhance the positive ones (An \& Lee, 2010). It could be said that parents remain central to regulating and guiding their children's television use to ensure that they engage in contents that positively influence their behavior. The roles parents play in regulating the media effects on their children is mainly determined by their attitude and concern towards the effect of television exposure (Nathanshon, 2001).
On the other hand there are studies whose results are inconsistent with this study. For example, (Cooper et al., 2005) found that there is a negative relationship between television watching and academic achievement. This might because the participant may differ in television content they watch.

Pertaining to the program commonly watched by students, this study found out that news is the commonly watched television program followed by comedy and drama. In line with study Sharew (2014) found out that news, drama and sport are the most frequently watched television programs. Rodman 2006, also states that television is the main source of news and information. It is the medium through which politics is conducted and it is humanity's main form of entertainment, it is also the world's most powerful sales tool."

The observed result indicated that the majority of students regulate their television program for themselves. They select the television contents and television watching hours for themselves. This finding is consistent with other research findings. For example, Sharew (2014) indicated that the television program selection left in the hands of children. In her study $62 \%$ of children participated in the study select the television program they watch for themselves.

\section{CONCLUSION}

Based on the major findings regarding students' television watching hours and their academic achievements this research came up with the following major findings. There is no significant relationship between hours of television watching and students' academic achievement. A significant majority of students watch television at least more than one hour a day. Almost half (45\%) of the students participated in this study regulates their television watching behavior for themselves. The following recommendations can be made based on these findings:

1. Further in-depth study should be conducted to examine variables like the content of television program and students' academic achievement and parental guide televissi9n programs and students' academic achievement. Moreover, the researchers suggest that study should be conducted on the basis of different levels of socio-economic status in relation to students' academic achievement.

2. Parents should appropriately mediate and control the television watching behavior of their children. 


\section{REFERENCES}

An, S., \& Lee, D. (2010). An integrated model of parental mediation: the effect of family communication on children's perception of television reality and negative viewing effects. Asian Journal of Communication, 20(4), 389-403. DOI: 10.1080/01292986.2010.49686Retrievedfromhttp://dx.doi.org/10.1080/01292986.2010.4 96864 on 23 June 2012

Anderson, D.R., Huston, A.C, Schmitt, K.L., Linebarger, D.L., and Wright, J.C. (2001). Early childhood television viewing and adolescent behavior: The recontact study. Monographs of the Society for Research in Child Development, 66 (Serial No. 264).

Barr, R., Lauricella, A., Zack, E. \& Calvert, S.L. (2010). Infant and early childhood exposure to adult-directed and child-directed television programming: Relations with cognitive skills at age four. Merrill Palmer Quarterly, 56, 21-48.

Bushan, C. (1992). Educational Communication by Television. Bharatia Skikshan, 2(8).

Comstock, G., \& Scharrer, E. (1999). Television: What's on, who's watching, and what it means? San Diego, CA: Academic Press.

Cooper, H., Valentine, J. C., Nye, B., \& Lindsay, J. J. (1999). Relationship between five after school activities and academic achievement. Journal of Educational Psychology, 91(2), 369-378.

CPB \& PBS (2011). Findings from Ready to Learn 2005 2010. Washington, D.C.: The Corporation for Public Broadcasting

Endawoke, Y. (2011). Basic principles and Applications of Research methodologies. Addis Ababa. Alpha printing press

Ennemoser, M., \& Schneider, W. (2007). Relations of television viewing and reading: Findings from a 4-year long longitudinal study. Journal of Educational Psychology, 99, 349-368.

Fortman, K. K. J., Clarke, T. L., \& Austin, E. W. (1998). Let's talk about what we're watching: Parental mediation of children's television viewing. Communication Research Report, 15(4) 413-425. doi: http://dx.doi org/10.1080/08824099809362141

Gunter, B., \& McAleer, J. (1997). Children and television ( $2^{\text {nd }}$ ed.). London and New York: Taylor \& Francis e-Library.

Hancox, R.J., Milne, B.J., \& Poulton, R. (2005). Association of television viewing during childhood with poor educational achievement. Archives of Pediatric Adolescent Medicine, 159, 614-618.

Henke, L. L. (1999). Children, advertising, and the Internet: An exploratory study. In Advertising and the World Wide Web (pp. 83-90). London: Psychology Press.
Huston, A. C., Wright, J. C., Marquis, J., \& Green, S. B. (1999). How young children spend their time: Television and other activities. Developmental Psychology, 35, 912-925.

Nathanson, A. I. (2001). Parent and child perspectives on the presence and meaning of parental television mediation. Journal of Broadcasting \& Electronic Media, 45, 210220. Retrieved from http://www.tandfonline.com/doi/ abs/10.1207/s15506878jobem4502_1\#.U0sIgqiSz-s

Neuman, W. L. (1997). Social Research Methods: qualitative and quantitative approaches, ( $5^{\text {th }}$ ed.). New York: Pearson Education.

Sandstig, G., Johansson, B., \& Ringsberg, K. (2013). The behavioral consequences of parents presumed media influence on restrictive mediation and co-viewing/ using media. Journalism and Mass Communication, 3(7), 452-463.Schumann, D.W., \& Thorson, E. (Eds.). Advertising and the World Wide Web. Advertising and consumer psychology (pp. 73-80). Mahwah, N.J., USA: Lawrence Erlbaum Associates, Inc.

Santrock, J.W (2005). Children $\left(10^{\text {th }}\right.$ ed.), New York: McGraw-Hill, 372.

Sharew, T. (2014). Parental Concern Towards The Effect Of Inappropriate Television Content On Children And The Practice Of Parental Television Mediation In Bole Sub City, Addis Ababa (Unpublished MA thesis). AAU.

Shastri, J. \& Mohite, P. (1997). Television viewing pattern of primary school children and its relationship to academic performance and cognitive skills. International Journal of Early Years Education, 5, 152-160.

Stevens, T., Barnard, L., \& To, Y.M. (2009). The association between television viewing and achievement: The impact of optimal viewing across time. Teachers College Record, January 2009 Volume, n.p.

Syed, N.A. (2010). Influence of TV watching on study habits and academic achievement of secondary school students in relation to socio-economic status (Unpublished M.Phil. dissertation), University of Kashmir.

Tafesse, T. (2006). News Coverage of Regions in Ethiopia: The Case of Etv Amharic Broadcast (Unpublished MA Thesis). AAU.

Valkenburg, P. M., Krcmar, M., Peeters, A. L. \& Marseille, N. M. (1999). Developing a scale to assess three styles of television mediation: "Instructive mediation," "restrictive mediation," and "social co-viewing". Journal of Broadcasting \& Electronic Media, 43(1), 52-66, DOI: $10.1080 / 08838159909364474$

Yilma, N. (2007). A critical analysis of Ethiopian broadcasting media regulation 1991-2007 (Unpublished MA thesis), AAU. 